\title{
Bibliographical Activity in the West and North West since 1974
}

\author{
Peter E. Greig
}

THE TITLE OF THE I978 ANNUAL MEETING OF THE BIBLIOGRAPHICAL SOCIety of Canada is 'Retrospect \& Prospects: A Review of Developments in Western and Northwestern Bibliography since 1974.' As indicated in the subtitle, the geographical scope of the papers which will be presented today has a specific regional context. Regionalism in a bibliographical context is rarely a liability; the underlying principles and standards which are applied in national and international bibliographical activity are simply taken for use at a more precise and manageable level. Indeed, a valid contribution at any one of these levels ultimately represents a contribution at the other two levels as well.

The significance of the date in the annual meeting title is an indication of the importance of the National Conference on the State of Canadian Bibliography - held from May 22 to May 24, I974, at the University of British Columbia in Vancouver - as a formative and influential stage in the awareness of the bibliographical situation in this country. This meeting today marks the first occasion at which it is possible to publicly review the bibliographical situation since I974. As such, it is also the first time that a review of the outcome and subsequent history of the National Conference on the State of Canadian Bibliography is feasible.

The other papers to be presented in the course of this annual meeting are devoted to specific subject or format areas of bibliographical activity in the West and North West. The purpose of this paper is to establish the background context for these more specialized discussions by following up the outcome of the National Conference on the State of Canadian Bibliography. Some attempt will be made as well to suggest possible areas of concern in the future development of bibliographical activity in these regions.

At the close of the National Conference on the State of Canadian Bibliography, a committee, composed of George Piternick and Basil Stuart-Stubbs, drafted a main resolution and sixty-two recommendations. These were based on the formal resolutions, or statements of consensus, of the various study groups, and on the resolutions or recommendations proposed by individual conference participants. The resolution was formally adopted and the recommendations were accepted in principle. 
The outcome of the main resolution will be discussed in detail shortly. For the moment it is sufficient to recall that it called for the creation of a National Advisory Council on Bibliographical Services for Canada. The text of the resolution indicated the composition of the proposed Council's membership and suggested the principal functions which it should undertake. The recommendations ranged from the general to the specific, and from national contributions to universal bibliographical control to purely sub-regional activities. The majority of the recommendations suggest the need for a specific tool with a set, and often limited, purpose. A few of the recommendations, however, indicate a concern for the creation of conditions which will support more effective bibliographical work in Canada.

The text of the resolution and recommendations, as with the majority of the papers delivered at the National Conference, was made available in photocopy almost immediately. With some similarity to the distribution of Russian underground literature these photocopies have been circulated to a wider audience by the bibliographical activists who attended the National Conference. In 1977, after various editorial and technical problems had been resolved, these increasingly faded and worn photocopies were superseded by the National Library of Canada's publication of the full proceedings of the National Conference.

As a matter of record the National Conference proceedings were produced in an edition of I,200 English language copies and 500 French language copies. The April I 978 figures from the Printing and Publishing Centre of Supply and Services Canada indicate that 663 copies of the English language text and 440 copies of the French language text have been distributed already. These distribution figures offer a fair indication of the continuing interest in the National Conference and of the impact of the National Conference on the Canadian bibliographical consciousness.

The delay in the formal publication of the National Conference proceedings may have lessened some of the initial euphoria with which participants left Vancouver. However, the general availability of the texts, particularly the text of the main resolution and the recommendations, inspired a general atmosphere conducive to the critical appraisal of bibliographical activities in Canada.

Immediately following the National Conference, its prime organizer, Anne Piternick, communicated the resolution and the recommendations to some fifty Canadian public and private agencies, associations, and institutions concerned with bibliographical work. During the three years of grace which preceded the formal publication of the National Conference proceedings, these bodies had time to consider and respond to the general outcome of the National Conference and to some of the more specifically directed recommendations. 
At the request of the Board of Directors and the Council of the Canadian Library Association, the Canadian Association of College and University Libraries (CACUL) formed a committee to study the resolution and recommendations of the National Conference. The report of this committee was submitted in October 1974 and subsequently published in the Canadian Library Journal. A particularly useful outcome of this study of the National Conference recommendations was their rearrangement into three categories: Canadian needs, regional needs, and subject needs.

These three categories were further defined in terms of specific bibliographical projects and improvements. In the case of Canadian needs a further sub-category was added for recommendations concerning the recognition of bibliographical activity, and a sub-category for recommended improvements to existing bibliographical tools was introduced under subject needs. This reorganization of the recommendations was adopted in the National Library of Canada's formal publication of the National Conference proceedings in 1977. Another important conclusion of the CACUL committee study was that the majority of the recommendations were considered to fall within the purview of the proposed National Advisory Council.

The resolution adopted at the National Conference, as noted, proposed the establishment of a National Advisory Council on Bibliographical Services. There was general support of this resolution among the various bodies contacted by Anne Piternick following the National Conference. This correspondence was forwarded to the Secretary of State who ultimately referred the matter to the National Librarian. The latter discovered a close similarity between the activities recommended for the National Advisory Council and those of the National Library Advisory Board. In January 1975 the Committee on Bibliographical Services for Canada was established as a committee of the National Library Advisory Board.

The Committee's membership reflects that proposed in the National Conference resolution. The members include invited representatives from key Canadian agencies, associations, and institutions concerned with bibliographical activity. The chairman of the Committee is a member of the National Library Advisory Board. The post is currently held by Francess G. Halpenny, who succeeded Margaret Williams in November 1977.

The original members of the Committee include representatives from the Advisory Board on Scientific and Technological Information, the Association pour l'avancement des sciences et des techniques de la documentation, the Bibliographical Society of Canada, the Bibliothèque nationale du Québec, the Canada Council (now the Social Sciences and Humanities Research Council of Canada), the Canada Institute for Scientific and Technical Information, the Canadian Library Association, and the National Library of Canada. In 1976 the Committee membership was enlarged to reflect the publishing commu- 
nity with representation from the Book \& Periodical Development Council and from the Conseil supérieur du livre. At the same time an observer from the National Library of Canada was named to the Committee. The Committee is also empowered to invite temporary representatives to individual meetings whenever a specific expertise or group interest is required.

From the outset the National Library of Canada undertook to provide a secretary for the Committee. In 1977, in recognition of the importance of the Committee's role, the National Library of Canada created a permanent Committee Secretariat to facilitate and to further the Committee's work.

The Committee's terms of reference, as drafted by its members at their first meeting in May 1975 and subsequently approved by the National Library Advisory Board, are substantially the same as those proposed in the main resolution adopted at the National Conference on the State of Canadian Bibliography. The Committee is to determine bibliographical needs in Canada, to assign priorities for support of bibliographical activities, to recommend support of bibliographical activities to funding and controlling bodies and agencies, and to assist in the coordination of bibliographical activity in Canada. 'Bibliography, in this context, is defined as the identification, description, and dissemination of recorded information. To this definition, taken from the National Conference's main resolution, the members of the Committee have added a significant precision by expressly noting that the definition includes both indexing and abstracting as forms of bibliographical activity.

The Committee members began their review of the National Conference recommendations at the Committee's first meeting in May 1975. It was recognized that the list of sixty-two recommendations accepted in principle at the National Conference did not reflect all of the levels and areas of bibliographical concern expressed in 1974. The first step taken by the Committee members, therefore, was to re-examine the papers presented at the National Conference to re-establish the full and original context of each of the sixtytwo recommendations accepted in principle and to extract other recommended bibliographical activities which had not been formally recorded. All of these recommendations were assembled in a single Committee document for discussion at the October 1975 meeting.

The mixed nature of the recommendations, both in terms of implied national / regional / sub-regional levels and in the context of widely scattered subject emphases, only became fully apparent at this time. Committee members also recognized that various developments in bibliographical activity had already taken place or were in process and that these would affect any consideration and priority ordering of the National Conference recommendations.

Committee members also became aware that more basic information was 
required if the recommendations were to be effectively evaluated. Information was required on the training or education available for bibliography in this country, on the standards operative in and applicable to Canadian bibliographical work, on the general criteria for the evaluation of bibliographical activity, and on the financial support available for bibliographical research and publication in Canada.

A research programme designed to investigate each of these areas was established by the Committee in February 1976. To some extent the investigations called for in the research programme pre-empted a more detailed study of the National Conference recommendations. Preliminary reports on 'Bibliographical Standards Used in Canada' and on 'Criteria for Enumerative Bibliographical Project Evaluation' have already been received from Committee members and are being edited for publication.

In the context of training or education available for bibliographical activity a preliminary list of Canadian library school courses in bibliography, including abstracting and indexing, was compiled by Anne Piternick. Recently she has provided a more detailed report on the training and educational facilities available to indexers and abstracters in Canada in a paper presented at the I978 annual meeting of the Indexing and Abstracting Society of Canada. The Committee is currently preparing a model programme to provide instruction in enumerative bibliography with a basic research strategy suitable for any subject field. The immediate aim of this model programme is to produce a short presentation, in an audio-visual form, on bibliographical control and the necessity of bibliographical standards.

The investigation of funding support available for bibliographical activity in Canada - early recognized as a major area of concern by the Committee has not yet produced any conclusive results. The Committee now realizes that there is a very definitive need to promote recognition of the needs and value of bibliographical activity, particularly among granting agencies. Realizing that the Committee was not alone in its perception of this need, the Committee chairman sent an open letter on this question to all of the Learned Societies in May I978. The object of this appeal is to identify other agencies and associations investigating the funding of bibliographical activity, to pool the available information, and to coordinate future enquiries in this area.

Each of the areas under investigation by Committee members in the research programme is intended to facilitate the over-all task of the Committee by providing the means to identify, evaluate, and assign priorities to bibliographical needs and bibliographical activities. At the same time it was felt that more information was required in certain specific areas of bibliographical activity, necessitating subject expertise not immediately present among the Committee's members. The Committee therefore invited specialist reports to assist its decision-making, notably on the progress of the $\mathrm{Na}$ - 
tional Library of Canada's retrospective bibliography project, on Canadian music, on Canadian children's literature, and on materials for the visually and physically handicapped.

The detailed study of the National Conference recommendations by Committee members was initially limited to those recommendations which impinge on national bibliographical concerns. However, even this sub-study was interrupted and delayed by another area of investigation which was drawn to the Committee's attention. At the Committee's second meeting in I975 the National Librarian requested that Committee members investigate the urgent problems confronting Canadian abstracting and indexing services. The Committee was encouraged to undertake this study because of its own expressed interest in and concern for Canadian abstracting and indexing. It was also evident that such a study would be a useful exercise inasmuch as it reflected the same concerns in miniature which motivated the Committee's more general investigation of the needs of and the priorities in Canadian bibliographical activities.

The Committee's initial step was to undertake a survey of all Canadian abstracting and indexing services with a publicly-available product in February 1976. The returns from this survey indicated that coverage, financing, editorial production, and technical production were all key areas of concern for the Canadian services which responded. On the basis of the survey results the Committee convened a workshop with representatives from the responding abstracting and indexing services in March 1977. A background directory of the services attending the workshop, based on the survey returns and other documentary sources, was prepared by the Committee Secretariat and distributed prior to the meeting.

After two days of discussion and deliberation the workshop participants proposed a number of recommendations in the four key areas of concern identified from the survey. These recommendations, revised by the Committee, were approved by the National Library Advisory Board in November 1977. Since that date the Committee Secretariat has worked to distribute the recommendations to implementing bodies and to implement those of the recommendations which the Committee can realistically undertake itself.

One workshop recommendation, proposing the establishment of an association of indexers and abstracters, was acted upon immediately. An open meeting on this question was held during the 1977 annual conference of the Canadian Library Association, and the meeting participants voted in favour of establishing such an association. The Committee Secretariat, until recently, assisted the fledgling Indexing and Abstracting Society of Canada through the provision of a mailing address and general administrative services.

Despite the challenges of these related concerns, Committee members 
have maintained a vital interest in the recommendations of the National Conference. Some of the difficulties of this study - the mixed nature of the recommendations and the fact that the recommendations were in circulation for a full year before the Committee held its first meeting - have already been mentioned. In resuming a more detailed examination of the National Conference recommendations, the Committee realizes that a definite effort must be made to create a clearinghouse for information on Canadian bibliographical activities if the Committee is to effectively carry out its mandate. In order to identify the needs of and to assign priorities to bibliographical activities Committee members must be aware of the existing bibliographical tools for Canadian materials, of the new and improved tools recommended for Canadian materials, and finally, of the bibliographical work already in process.

The Committee Secretariat is already cooperating with the Bibliographical Society of Canada, in connection with the planned third edition of the Bibliography of Canadian Bibliographies, to ascertain what bibliographical work has been done in Canada. The study of the recommendations of the National Conference on the State of Canadian Bibliography will offer some guidance as to what bibliographical work is necessary. The task which remains, in some ways the most difficult, is to discover what bibliographical work is presently underway and to relate it to the foregoing. With a view to learning more about this on-going bibliographical work the Committee is especially pleased at the opportunity to participate in the Society's present annual meeting programme. This meeting, apart from providing an opportunity for the Committee to outline its work and indicate some of its concerns, has prompted the Committee to shift its study of the needs expressed in the National Conference recommendations from a uniquely national level to a regional plane. In evidence of this, and by way of conclusion, I should like to refer briefly to the two documents that have been prepared and made available for this meeting.

The Canadian West et the North: A Bibliographical Overview was compiled by Dorothy E. Ryder, Reference Collection Development Specialist in the National Library of Canada, at the request of this meeting's organizers. This list fulfils to some extent the first stage of the clearinghouse mentioned above by its indication of the general bibliographical activity in these regions to the present day. The difficulty of keeping even such a recently compiled list up to date was made apparent just before this meeing when Bruce Peel asked that the recently published Western Canada since 1870: A Select Bibliography, by Alan F.J. Artibise, which is not included in Dorothy Ryder's list be publicized. The Committee's own particular contribution to today's meeting is the Subject Inventory of Regional and Western Recommendations Extracted from the National Conference on the State of Canadian Bibliography.

These two documents reflect, on a partial basis, only two-thirds of the type of information which the Committee must have to create its clearinghouse of 
information on Canadian bibliographical activity and to operate effectively within its terms of reference. While working to produce these two elements at the national level, the Committee is also engaged in producing an inventory of Canadian bibliographical work in progress which will form the last block of information necessary to an effective planning of Canada's bibliographical future.

[Note: Copies of the Subject Inventory of Regional and Western Recommendations Extracted from the National Conference on the State of Canadian Bibliography are available from: The Secretary, Committee on Bibliographical Services for Canada, National Library of Canada, 395 Wellington Street, Ottawa, Ontario K I A oN4.] 